\title{
Identificando oportunidades de colaboração no contexto governamental: um estudo de caso na elaboração de planos diretores municipais
}

\author{
Jonas Henrique Ribeiro Paula, Melise Maria Veiga de Paula \\ Programa de Pós-Graduação em Ciência e Tecnologia da Computação \\ Universidade Federal de Itajubá (UNIFEI) - Itajubá - MG - Brasil \\ jonashenrq@gmail.com, melise@unifei.edu.br
}

\begin{abstract}
The objective of this article is, based on a model that proposes an approach to promote popular participation through the $3 C$ Collaboration Model, to propose a collaborative workflow of the process of creating a municipal master plan, identifying together the opportunities for collaboration with possibility of using technologies to expand such opportunities. The Business Process Model and Notation (BPMN) will be used to map the processes and the opportunities for collaboration will be based on the $3 C$ Collaboration Model.
\end{abstract}

Resumo. $O$ objetivo deste artigo é, a partir de um modelo que propõe uma abordagem para promover a participação popular através do Modelo $3 C$ de Colaboração, propor um workflow colaborativo do processo de criação de um plano diretor municipal, identificando em conjunto as oportunidades de colaboração com a possibilidade do uso de tecnologias para ampliar tais oportunidades. O Business Process Model and Notation (BPMN) será utilizado no mapeamento dos processos e as oportunidades de colaboração serão baseadas no Modelo 3 C de Colaboração.

\section{Introdução}

Atualmente existem diferentes iniciativas que investigam oportunidades de melhoria nos processos que são executados no contexto de governo. Uma das vertentes pesquisadas são as oportunidades para efetivar ou ampliar a colaboração. Já em 2012, por exemplo, Ae Chun et al. (2012) descrevem sete trabalhos de pesquisa relativos ao tema de colaboração em governo eletrônico.

A participação popular pode ser entendida sob essa perspectiva como uma das alternativas para ampliar essas oportunidades de colaboração. Em governos democráticos, existem diferentes instrumentos jurídicos criados para garantir a participação do cidadão no cenário político ampliando os espaços de colaboração entre governo e a sociedade [Oliveira et al. 2019].

No Brasil, a lei federal denominada Estatuto da Cidade [Brasil 2001] pode ser considerada um exemplo. Esta lei determina que a gestão pública municipal deve elaborar um planejamento estratégico da cidade baseando-se em diversos instrumentos legais, sendo o plano diretor municipal (PDM) um destes instrumentos. Contudo, a elaboração do PDM é, inerentemente, um processo colaborativo pois envolve diversos atores em sua execução, inclusive a sociedade [Santoro et al. 2005]. 
Embora, seja reconhecida a importância da colaboração nesse contexto, ainda há importantes questões a serem investigadas. No caso mencionado, por exemplo, o Estatuto da Cidade não define de forma clara as regras e condições para que, na elaboração do plano diretor, a colaboração entre os diferentes atores envolvidos nesse processo seja efetiva de forma a garantir a participação do cidadão e dos agentes envolvidos.

\section{Apresentação do Problema}

O Estatuto da Cidade é uma lei federal [Brasil 2001] que determina como deve ser feita a política urbana em todo o país. O objetivo é garantir o direito à cidade para todos. Um dos instrumentos legais que diz como o estatuto deverá ser aplicado em cada município é o Plano Diretor Municipal (PDM). O PDM determina como o poder público e a iniciativa privada devem atuar na oferta dos serviços públicos essenciais e determina normas para a construção nos espaços urbano e rural. O principal objetivo é assegurar melhores condições de vida, de forma democrática, para a toda população [Santoro et al. 2005].

A elaboração de um PDM envolve a colaboração entre pessoas de diversas áreas do conhecimento, diferentes departamentos da gestão e a sociedade com um objetivo comum: identificar quais são as demandas da cidade e da população. Na primeira etapa de elaboração do PDM, pode ser formada uma equipe técnica e diferentes grupos de trabalho, contudo, a lei exige a formação de um núcleo gestor cujo objetivo é acompanhar as atividades desenvolvidas tanto pela equipe técnica quanto pelos grupos de trabalho (GTs). O núcleo gestor deve ser, obrigatoriamente, representativo, ou seja, os diversos segmentos da sociedade e lideranças do município devem ser representados como, por exemplo, empresas privadas, ONGs, movimentos sociais, sindicatos rurais e/ou comercias, dentre outros. Essa composição depende essencialmente das especificidades do município [Santoro et al. 2005]. Além disso, durante todo o processo de elaboração do PDM, em diversos momentos, a população deve ser consultada tanto para a realização dos diagnósticos de problemas quanto para a aprovação das determinações propostas.

Considerando esse cenário, é correto afirmar que a colaboração entre esses diferentes atores pode ser complexa, principalmente, porque não existe atualmente um modelo de elaboração do plano que permita o planejamento e a visualização do fluxo de trabalho desses atores de forma organizada. No entanto, todos os atores envolvidos precisam colaborar e participar para que este instrumento seja elaborado de maneira efetiva, democrática e não enviesada.

\section{Proposta de Solução}

De uma forma geral, o contexto de pesquisa desse trabalho é investigar estratégias para estimular a colaboração entre as pessoas envolvidas em processos governamentais que necessitam de diferentes atores em sua execução e a participação popular. No governo, existem diversos processos inseridos nesse contexto, sendo um destes a elaboração de um PDM.

A base para a proposta de solução é o modelo apresentado por Oliveira et al. (2019) cujo objetivo é propor uma abordagem para facilitar a participação popular através do Modelo 3C de Colaboração. No modelo 3C, a colaboração é analisada sob três dimensões: comunicação, coordenação e cooperação. A comunicação é caracterizada pela troca de mensagens, pela argumentação e pela negociação entre pessoas; a coordenação é caracterizada pelo gerenciamento de pessoas, recursos e atividades; e a cooperação é 
caracterizada pela atuação conjunta no espaço compartilhado para a realização das atividades [Fuks et al. 2011].

A utilização do Modelo 3C de Colaboração na computação pode ser observada em alguns trabalhos, sendo um deste o de Silva et al. (2019). Em Silva et al. (2019) os autores analisaram os modelos de colaboração de seis softwares editores de ontologia ao relacionar as funcionalidades das ferramentas com o modelo.

Oliveira et al. (2019), os autores discutem questões especificas para os 3 elementos do modelo: cooperação, coordenação e comunicação. Nesse trabalho, o foco será a camada de coordenação do modelo, a solução proposta é a construção de um workflow colaborativo através do mapeamento do processo de elaboração de um PDM, identificando em conjunto as oportunidades de colaboração com a possibilidade do uso de tecnologias para ampliar tais oportunidades. Embora não seja objetivo desse trabalho desenvolver uma ferramenta específica, também está sendo analisada a possibilidade de criação de uma plataforma web que auxilie na execução dos processos executados na elaboração do PDM.

Esta pesquisa está sendo desenvolvida em parceria com o Núcleo Estratégico Interdisciplinar em Resiliência Urbana (NEIRU) que é um núcleo de pesquisa e extensão vinculado a Universidade Federal de Itajubá, sendo um de seus serviços prestados, a revisão de planos diretores municipais. Assim, o mapeamento será realizado nos projetos executados pelo NEIRU.

Para o mapeamento do processo será utilizado o Business Process Model and Notation (BPMN). O BPMN é um padrão para modelagem de processos de negócios que fornece notação gráfica para especificar processos com base nas técnicas tradicionais de fluxograma tendo sido projetado para ser simplesmente compreensível por todas os atores interessados [Von Rosing et al. 2015].

\section{Projeto de Avaliação da Solução}

A avaliação da solução proposta deverá ser considerada sob duas perspectivas: o mapeamento BPMN do processo tendo como diretriz as oportunidades de colaboração, considerando os atores, as restrições e condições para que essa colaboração aconteça; e as tecnológicas identificadas que sustentam tais oportunidades.

Desta forma, a avaliação acontecerá em duas etapas: a primeira, deverá ser validado o mapeamento BPMN elaborado seguindo a estratégia de validação apresentada por Hochleitner e Oppl (2018) apud Obermeier et al (2014). Nesta estratégia, a validação consiste em verificar se o modelo retrata a realidade do processo do negócio e avalia se o modelo utiliza a sintaxe correta da linguagem de modelagem escolhida. A segunda etapa tem por objetivo validar a adequação das tecnologias identificadas. Toda a validação será realizada considerando os projetos executados no NEIRU como cenários reais para responder os questionamentos e aprofundamento das questões a serem levantadas.

\section{Atividades Realizadas}

Está sendo realizado um mapeamento sistemático da literatura (MSL) com foco em estudos sobre a criação e/ou uso de workflow colaborativo no governo, tendo sido selecionados 46 artigos nas principais bases científicas: IEEE Xplore, ACM Digital 
Library, Scopus e ScienceDirect. Atualmente, o mapeamento está na fase de publicação no qual os resultados encontrados estão sendo formalizados em um artigo.

\section{Considerações Finais}

Baseando-se no modelo que tem por objetivo propor uma abordagem para promover a participação popular através do Modelo 3C de Colaboração de Oliveira et al. (2019), focando na camada de coordenação deste modelo. É proposto a construção de um workflow colaborativo dos processos executados na elaboração de um PDM utilizando o BPMN e identificando em conjunto as oportunidades de colaboração em cada processo, bem como as tecnologias que apoiem e fomentem tais oportunidades.

Espera-se ao fim desta pesquisa que os resultados aumentem a eficiência do processo de elaboração do PDM e que de certa forma, auxilie os aspectos de participação e colaboração deste processo. Também se espera que a experiencia do mapeamento, observando as oportunidades de colaboração, sejam utilizadas no mapeamento de outros processos governamentais.

\section{Referências}

Ae Chun, S., Luna-Reyes, L. F. and Sandoval-Almazán, R. (2012). Collaborative egovernment. Transforming Government: People, Process and Policy, v. 6, n. 1, p. 512 .

Brasil (2001). Lei No 10.257, de 10 de jul. 2001. Regulamenta os arts. 182 e 183 da Constituição Federal, estabelece diretrizes gerais da política urbana e dá outras providências. Diário Oficial, Brasília, 11 jul. 2001.

Fuks, H.; Raposo, A.; Gerosa, M. A.; Pimentel, M.; Filippo, D. and Lucena, C. J. P. (2011) "Teorias e Modelos de Colaboração" In Pimentel, M. and Fuks, H. (Org.). Sistemas Colaborativos. Rio de Janeiro: Elsevier. cap. 2, p. 16-33.

Hochleitner, F. and Oppl, S. (2018). Validation of Business Process Models through Interactively Enacted Simulation. In Proceedings of the 10th International Conference on Subject-Oriented Business Process Management - S-BPM One '18. ACM Press.

Obermeier, S., Fischer, H., Fleischmann, A. and Dirndorfer, M. [Eds.] (2014). Geschäftsprozesse realisieren: ein praxisorientierter Leitfaden von der Strategie bis zur Implementierung. 2., aktualisierte Aufl ed. Wiesbaden: Springer Vieweg.

Oliveira, K. W. R. et al. (2019). Aplicação de um modelo de colaboração em um contexto de participação social. In: SIMPÓSIO BRASILEIRO DE SISTEMAS COLABORATIVOS (SBSC), 1., 2019, Rio de Janeiro. Anais do XV Simpósio Brasileiro de Sistemas Colaborativos. Porto Alegre: Sociedade Brasileira de Computação, sep. 2019. p. 52-57.

Santoro, Paula Freire, Cymbalista, Renato e Cardoso, Patrícia de Menezes (2005). Plano diretor: participar é um direito! São Paulo: Pólis.

Silva, M. F., Martins, D. L., Santana, D. V. and Siqueira, J. (2019). Análise dos modelos colaborativos de softwares para edição de ontologias por meio do Modelo $4 \mathrm{C}$ de Colaboração. Em Questão, v. 25, n. 1, p. 267. 
Von Rosing, M., White, S., Cummins, F. and De Man, H. (2015). Business Process Model and Notation-BPMN. The Complete Business Process Handbook. Elsevier. p. 433457. 